Article

\title{
Dynamic Model of a Sustainable Water Resources Utilization System with Coupled Water Quality and Quantity in Tianjin City
}

\author{
Yutong Tian, Chunhui Li * (D), Yujun Yi, Xuan Wang and Anping Shu* \\ Key Lab of Water and Sediment Science of the Ministry of Education, School of Environment, \\ Beijing Normal University, Beijing 100875, China; 18810550713@163.com (Y.T.); yiyujun@bnu.edu.cn (Y.Y.); \\ wangx@bnu.edu.cn (X.W.) \\ * Correspondence: Chunhuili@bnu.edu.cn (C.L.); Shuap@bnu.edu.cn (A.S.)
}

Received: 12 April 2020; Accepted: 18 May 2020; Published: 22 May 2020

check for updates

\begin{abstract}
With the development of industrial and agricultural production and the social economy, the demand for water resources has gradually increased. In this paper, based on the principles of system dynamics, a sustainable water resources utilization model with coupled water quality and quantity is established using STELLA software to assess the sustainable use of water resources. The model includes two modules: a water supply module and a water quality module. The water supply module includes four sub-systems: economy, population, water supply, and water demand. The water quality module consists of an environmental sub-system. The model is suitable for Tianjin, where water resources are scarce. Calibration is performed using data from 2013-2016, and verification is performed using data from 2017. The simulation results are good. In order to compare the sustainable use of water resources in different development scenarios in Tianjin for 2025 , a sensitivity analysis is performed for each variable, and four decision variables are selected to establish four water resources use scenarios (Scenarios 1-4). The results show that, compared with scenario 1, water shortages in scenarios 2 and 3 are delayed. Scenario 4 , with stable economic growth and environmental consideration, can effectively resolve the contradiction between water supply and demand in the future, and is more conducive to the improvement of water quality. Finally, based on the above research, measures to solve water resources problems are proposed, in order to provide a reference for the sustainable use of water resources and optimization of water resources allocation in Tianjin.
\end{abstract}

Keywords: system dynamics; water resources; sustainable use; Tianjin; water quantity and quality

\section{Introduction}

Water is an indispensable material foundation for human survival and social development. With the rapid development of the economy, the problem of water resources management has become increasingly prominent. Water resources shortages severely restrict social and economic development and even threaten drinking water safety [1].

System dynamics appeared in 1956, in which, according to the feedback characteristics of internal components of a system as causality, the root cause of a problem is determined from the internal structure of the system, instead of using external interference or random events to explain the system [2]. System dynamics approaches have been widely used in sustainable development research [3]. In the field of water resources, they have also been used in the sustainable use of water resources, the balance of water supply and demand, water resources management, and determining the response of water resources to population and climate [4-10]. An object-oriented system dynamics method has been 
used to establish a model of the water resources system in the Yellow River Basin, with which the sustainability of the regional water resources systems was evaluated [11]. The effects of population growth and climate change on water resources in the Las Vegas Valley (LVV) in the semi-arid region of southern Nevada have been studied using a system dynamics model, combining water conservation and pricing policies to promote the sustainable development of water resources [12]. A system dynamics model of the Kairouan region using water stress has been established to assess the potential impact of water scarcity and socioeconomic policies on complex hydrological systems [13]. Using a system dynamics approach to consider potential water sources, potential water needs, and management tools, the impact of price differences on water scarcity was determined and the impact of expanding wastewater networks on groundwater resources was analyzed [9]. An object-oriented system dynamics model was established through a decision-making process for water resources exploration, and the correlation between the availability of water resources and the demand for water caused by industry, agricultural production, and population growth was obtained [14]. Combining system dynamics with geographic information systems (GIS) and proposing a new method called space system dynamics (SSD) to model feedback-based time and space dynamic processes, a single modeling framework was provided for the development of conceptually different models and modeling complex dynamic processes based on spatiotemporal feedback [12].

In the study of system dynamics, the modeling software STELLA (structure thinking experimental learning laboratory with animation) is capable of handling dynamic, non-linear, and high-order complex problems [15]. It has a highly respected, user-friendly operation interface, and has been increasingly widely used. Based on the theory of system dynamics and the use of the STELLA software, a sustainable water resources utilization model has been established. The model includes four sub-systems: a population system, an economic system, a water supply system, and a water demand system. It has been applied to Zhengzhou under severe water shortages [16]. STELLA was used to establish a water supply and demand system model. The model consists of water supply and residents, industry, agriculture, ecological environment, public water demand, and other sub-systems. The supply and demand situation in the Anhui Province has been studied [17]. An integrated method for system dynamics, orthogonal experimental design, and inexact optimization modeling of water resources management under uncertain conditions has been proposed, which uses STELLA for modeling and to combine inaccurate two-stage stochastic programming and credibility-constrained programming to obtain the optimal solution. Using this method, the allocation of multi-source water resources to multiple users in Dalian in a multi-year background was studied [18].

When applying the STELLA model in water resources management, water quality is often adjusted as a less important parameter. Therefore, in this study, we establish a system dynamics model for the sustainable use of water resources. The model includes two modules. The water supply module includes four sub-systems: economy, population, water supply, and water demand systems. The water quality module consists of a water environment sub-system. The proposed model is used to simulate Tianjin's water supply and demand system from 2018 to 2025, analyze the sensitive variables affecting water supply and demand, and then establish four scenarios by adjusting the sensitive variables to simulate and predict future water quantity and quality supply and demand conditions. The study is expected to provide a reference for alleviating the shortage of water resources in Tianjin and optimizing the allocation of water resources. We put forward feasibility suggestions for the rational planning and management of water resources in Tianjin and the realization of sustainable use of water resources.

\section{Methods}

\subsection{Study Area}

Tianjin City is located in the lower reaches of the Haihe River Basin, with dense river networks and numerous lakes (Figure 1). There are 19 first-class rivers which mainly flow through Tianjin, with a total length of $1100 \mathrm{~km}$. There are 109 secondary rivers, mainly for drainage, with a total length of $1890 \mathrm{~km}$. 
The Beihe River system, Yongding river system, Daqing river system, Zhangweinan Canal system, Haihe river system, and Heilonggang Yundong river system belong to the Haihe River Basin [10]. The Water Diversion Project from the Luanhe River to Tianjin is a large-scale water conservancy project, built in the 1980s. It includes the Luanhe River section, the Luanhe Canal, and the Yuqiao and Erwangzhuang Reservoirs. About 1 billion cubic meters of water are delivered to Tianjin every year.

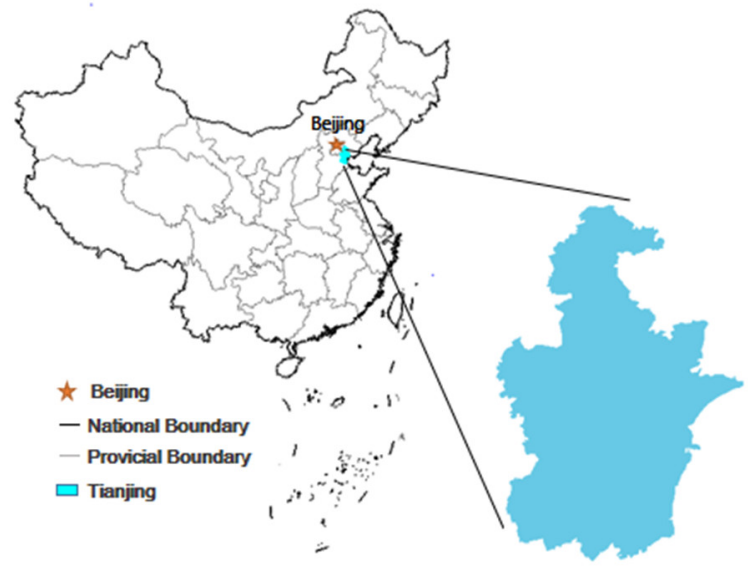

Figure 1. Administrative divisions of Tianjin.

Tianjin's water resources are relatively scarce, and the local water supply capacity is insufficient. In 2017, the total domestic water resources of the city were about 880 million cubic meters, an average reduction of $17.4 \%$ from the long-time average annual value. Groundwater resources amounted to 554 million cubic meters, an average decrease of $6.1 \%$ from the long-time average annual value. In recent years, with the rapid development of Tianjin's economy and the continuous improvement of the overall level of society, water consumption has increased. In 2017, its total water consumption was 2.87 billion cubic meters (in this article, billion means $10^{9}$ ), of which water consumption was 1.82 billion cubic meters, with a water consumption rate of $63 \%$.

\subsection{Data Source and Processing}

The research area of this study was Tianjin, the simulation period was 2013-2025, and the base year was 2013. The data used in this study came from the Tianjin Yearbook, the Tianjin Environmental Quality Briefing, the Tianjin Water Conservancy Briefing [19], the Tianjin National Economy and Social Responsibility Report, the Social Development Statistical Bulletin, and the Tianjin Environmental Statistics Annual Report.

Through the selection and analysis of the data, the parameters were divided into the initial values of the state variables, the values of the constants, and the values of the table functions, according to the different properties of the parameters [20]. The raw data are shown in Table 1. Missing values were unavoidable, due to problems such as data source collection and partitioning. However, as the purpose of this article was to predict future trend changes based on existing data, we adopted methods to avoid their use to improve accuracy [21]. 
Table 1. Raw data of water supply, demand, water environment, population, and economy of Tianjin from 2013 to 2018.

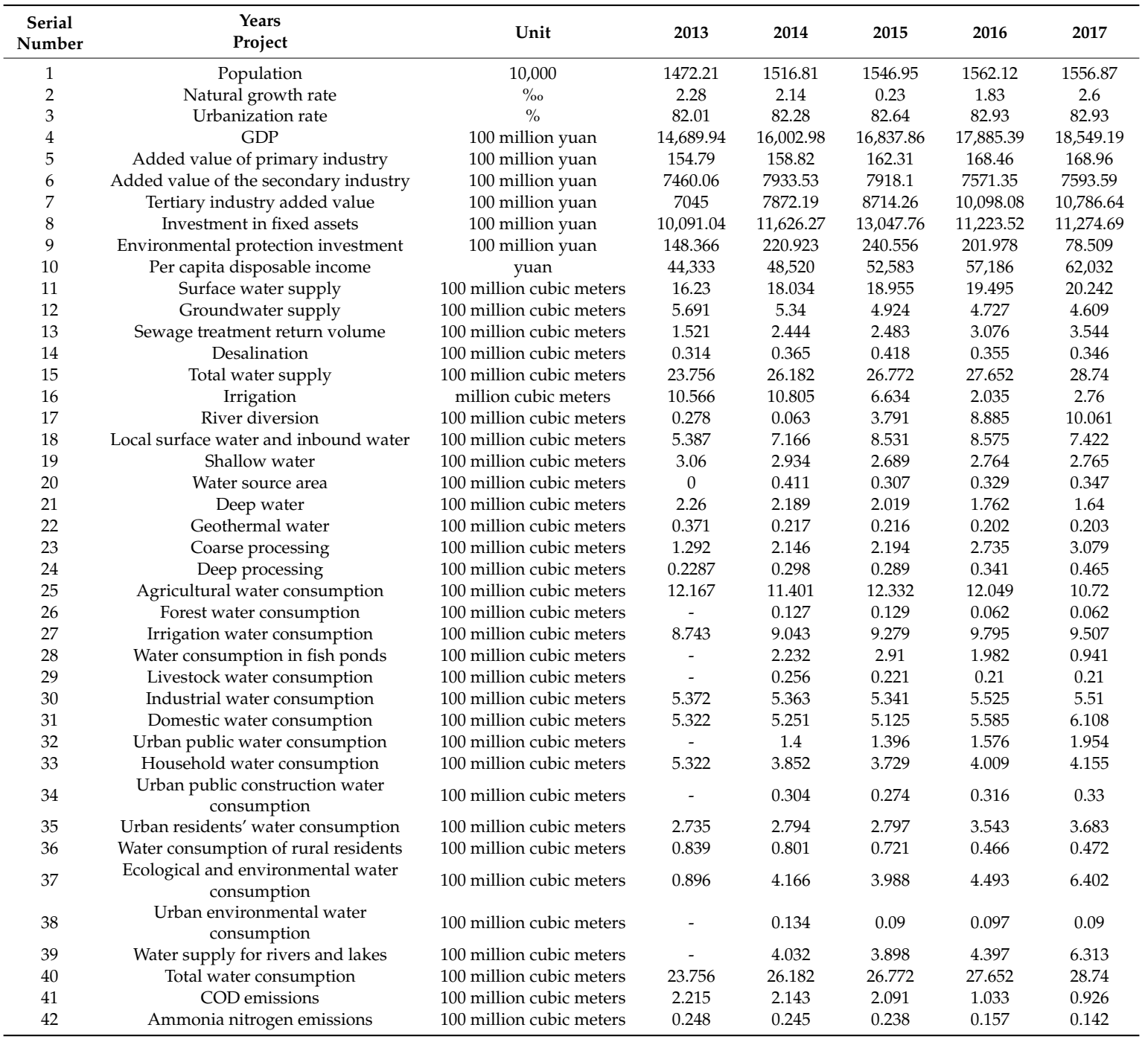

\subsection{Methods}

The main content of this article is the sustainable utilization of urban water resources, but water resources involve two factors: water quality and quantity. Therefore, in order to make the research more comprehensive, the above two factors must be included in the model as sub-modules. The water quantity module considers the economy, population, supply and demand, and other factors. The water quality module uses the two most influential and most common pollutants as assessment indicators. This served as the basis for the establishment of our system dynamics model for the sustainable use of water resources in Tianjin.

Before establishing our system dynamics model, we first performed a system analysis on the research object to determine our modeling goals. Then, according to the principles and methods of system dynamics, the system boundary and various variables of the system were determined, according to the modeling goals. Variables were then classified into state variables, rate variables, auxiliary variables, and so on, based on system element attributes [22]. The technical flow diagram of this paper is shown in Figure 2. 


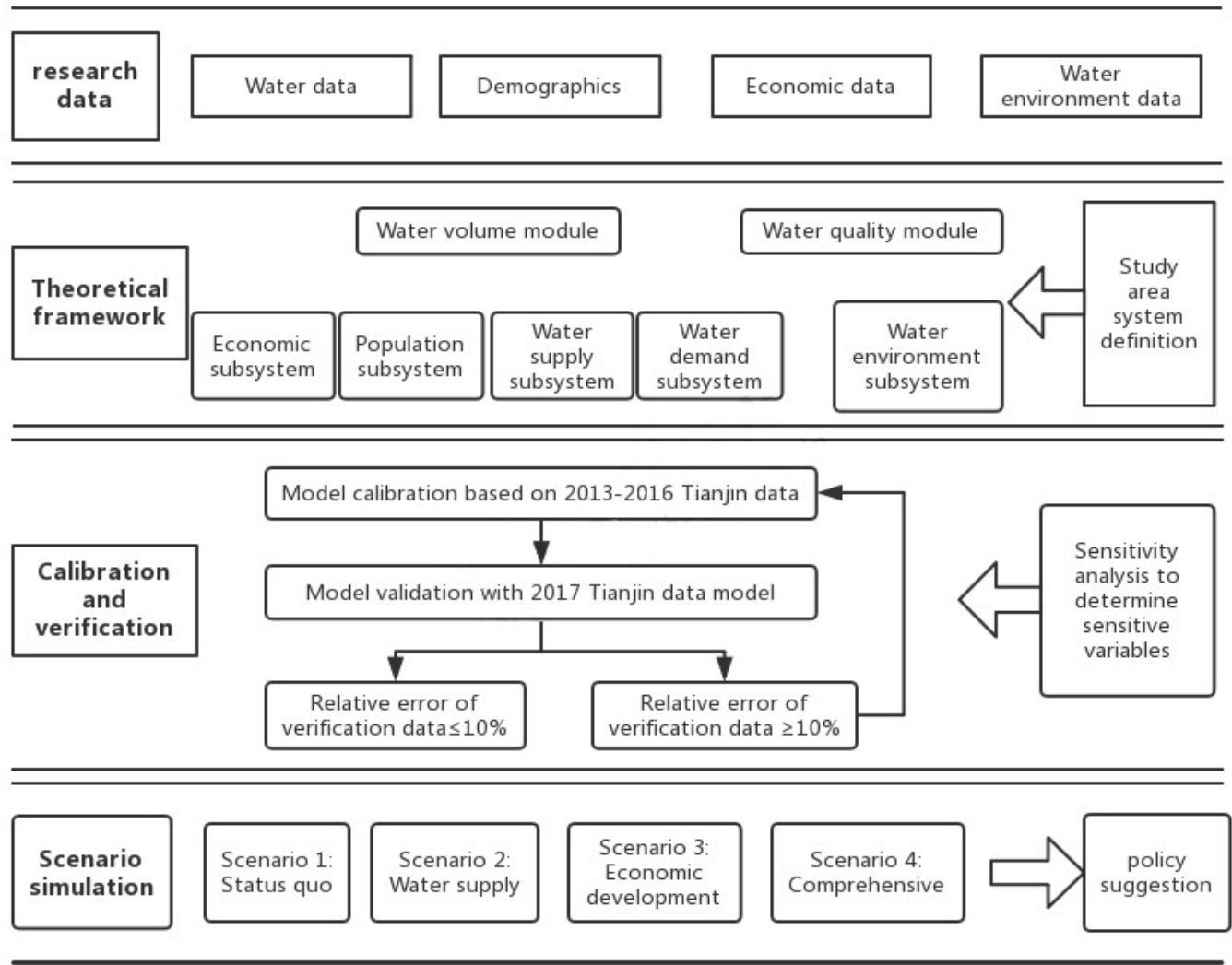

Figure 2. Technical route.

\subsubsection{Systematic Definition of Study Area}

We analyzed the relationships among various factors influencing the sustainable use of water resources, according to the characteristics of the current situation of water resources use in Tianjin and the availability and accuracy of the relevant data [23]. The boundary of the model system was determined to be the entirety of Tianjin city, including 15 districts and 1 county under the jurisdiction of the city. The 15 municipal districts were the Heping, Hedong, Hexi, Nankai, Hebei, Hongqiao, Dongli, Xiqing, Jinnan, Beichen, Wuqing, Baoqiao, Binhai New, Ninghe, and Jinghai Districts. Using STELLA V9.0.1, a special modeling software for system dynamics, a flow chart of the Tianjin water resources system, including the two sub-modules of water quantity and water quality, was established. The water volume module includes four sub-systems: population, agriculture, industry, and water supply and water demand. Each sub-system is interconnected and can affect one another.

\subsubsection{Model Establishment}

Causality analysis is a qualitative analysis of the system. Through causality analysis, the main structure of the system dynamics model can be preliminarily constructed, and the functional relationships between each variable of the system can be further defined to form the basis for operation of the system [24]. Our model used the administrative boundary of Tianjin as the model boundary, the time scale was from 2013 to 2018, and the time step was one year. The simulation period was from 2019 to 2025, the step was one year, and 2013 was the base year. According to the relationships between the sub-systems, the STELLA V9.0.1 software was used to simulate the system. The overall structure of the model is shown in Figure 3. The five major sub-system variables are shown in Table 2. 


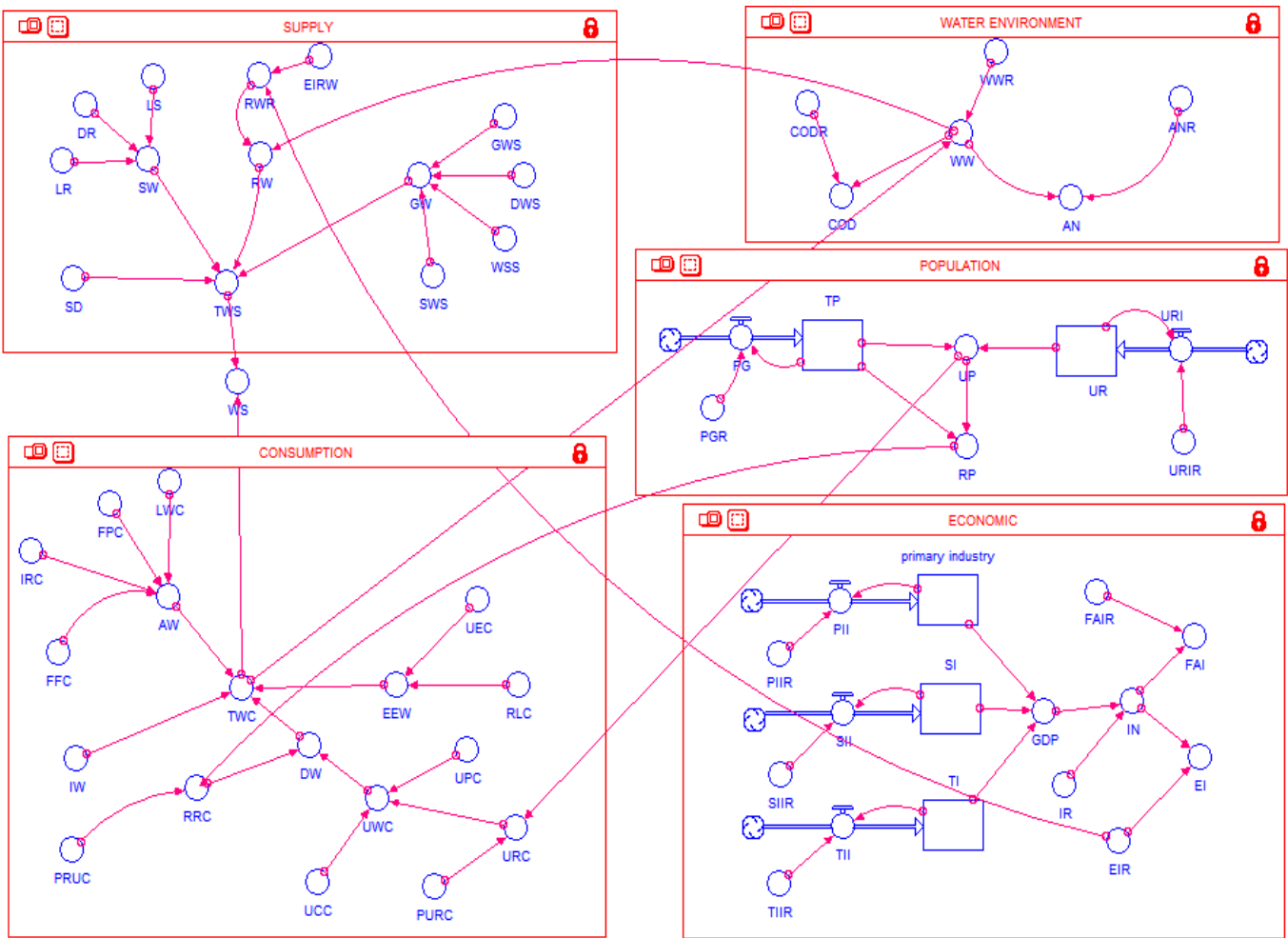

Figure 3. Tianjin Sustainable Water resources Utilization Model.

Table 2. The five major sub-systems of population, economy, water supply, water demand, and water environment.

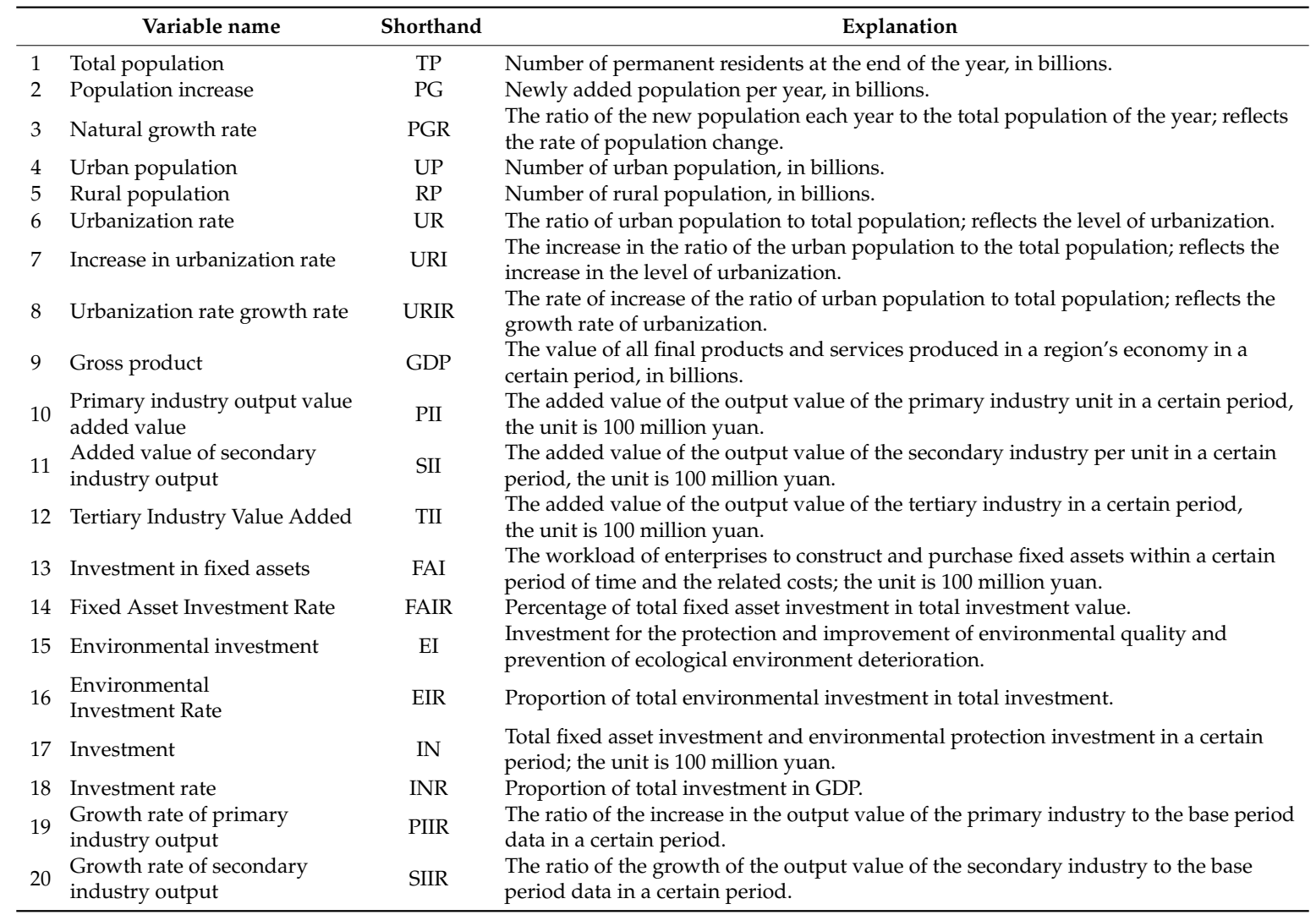


Table 2. Cont.

\begin{tabular}{|c|c|c|c|}
\hline & Variable name & Shorthand & Explanation \\
\hline 21 & $\begin{array}{l}\text { Tertiary industry output } \\
\text { value increase }\end{array}$ & TIIR & $\begin{array}{l}\text { The ratio of the increase in the output value of the tertiary industry to the base period } \\
\text { data in a certain period. }\end{array}$ \\
\hline 22 & Surface water supply & SW & Supply of crustal surface and water exposed to the atmosphere, in billion cubic meters. \\
\hline 24 & Wastewater treatment & RW & $\begin{array}{l}\text { Wastewater or sewage reused for production system or domestic miscellaneous use } \\
\text { after secondary and advanced treatments. }\end{array}$ \\
\hline 27 & $\begin{array}{l}\text { Water supply from } \\
\text { Luanhe River }\end{array}$ & LR & The amount of water introduced from the Luohe River, in billion cubic meters. \\
\hline 28 & $\begin{array}{l}\text { Water supply volume of the } \\
\text { Yinjiang River }\end{array}$ & DR & The amount of water introduced from the Danjiang River, in billion cubic meters. \\
\hline 29 & $\begin{array}{l}\text { Local surface water and } \\
\text { inbound water }\end{array}$ & LS & $\begin{array}{l}\text { Total surface water and the amount of water flowing into the area from the upstream, } \\
\text { in billion cubic meters. }\end{array}$ \\
\hline 32 & Deep water supply & DW & $\begin{array}{l}\text { The amount of water hidden in the permeable layer below the first impervious layer, } \\
\text { in billion cubic meters. }\end{array}$ \\
\hline 33 & Geothermal water supply & GW & $\begin{array}{l}\text { The amount of groundwater in the surrounding rock temperature above the observed } \\
\text { depth, in billion cubic meters. }\end{array}$ \\
\hline 34 & $\begin{array}{l}\text { Agricultural water } \\
\text { consumption }\end{array}$ & AWC & Total water used for irrigation and rural livestock, in billion cubic meters. \\
\hline 35 & Forest water consumption & FFC & Total amount of water used by forest fruit trees, in billion cubic meters. \\
\hline 36 & Irrigation water & IRC & Total amount of water used for irrigation, in billion cubic meters. \\
\hline 37 & Fishpond water consumption & FPC & Total water used for fishpond aquaculture, in billion cubic meters. \\
\hline 38 & Livestock water consumption & LWC & Total water consumption of rural livestock, in billion cubic meters. \\
\hline 39 & Industrial water consumption & IW & $\begin{array}{l}\text { The total amount of production water used in the industrial production process and } \\
\text { the domestic water used by employees in the factory area, in billion cubic meters. }\end{array}$ \\
\hline 45 & $\begin{array}{l}\text { Water consumption of rural } \\
\text { residents }\end{array}$ & RUC & Total domestic water consumption of rural households, in billion cubic meters. \\
\hline 46 & $\begin{array}{l}\text { Per capita water consumption } \\
\text { of urban residents }\end{array}$ & PURC & Per capita water consumption in urban households, in cubic meters. \\
\hline 47 & $\begin{array}{l}\text { Per capita water consumption } \\
\text { of rural residents }\end{array}$ & PRUC & Per capita water consumption in rural households, in cubic meters. \\
\hline 48 & $\begin{array}{l}\text { Ecological and environmental } \\
\text { water consumption }\end{array}$ & EEW & $\begin{array}{l}\text { The minimum amount of water required for the restoration and construction of the } \\
\text { ecological environment or to maintain the status of the current ecological environment. }\end{array}$ \\
\hline 49 & $\begin{array}{l}\text { Urban environmental water } \\
\text { consumption }\end{array}$ & UEC & $\begin{array}{l}\text { Water consumption to reach the level of urban ecological environment and maintain } \\
\text { the urban ecological balance; the unit is } 100 \text { million cubic meters. }\end{array}$ \\
\hline 50 & $\begin{array}{l}\text { Water supply for rivers } \\
\text { and lakes }\end{array}$ & RLC & $\begin{array}{l}\text { Total amount of supplementary water for landscape environment in rivers and lakes, } \\
\text { in billion cubic meters. }\end{array}$ \\
\hline 51 & Total water consumption & TWC & Total amount of water used by water users in the area, in billion cubic meters. \\
\hline 52 & COD emissions & COD & Total water use as a function of COD emissions gauge. \\
\hline 53 & Ammonia nitrogen emissions & AN & Total water use as a function of ammonia nitrogen emissions scale. \\
\hline 54 & COD emission rate & CODR & COD discharge rate in wastewater. \\
\hline 55 & $\begin{array}{l}\text { Ammonia nitrogen } \\
\text { emission rate }\end{array}$ & ANR & The rate of ammonia nitrogen discharge in wastewater. \\
\hline 56 & Total wastewater & WW & Total amount of wastewater in total water use, in billion cubic meters. \\
\hline 57 & Wastewater generation rate & WWR & Proportion of wastewater in total water use. \\
\hline 58 & Wastewater reuse rate & RWR & $\begin{array}{l}\text { The ratio of the amount of wastewater or sewage reused to the production system or } \\
\text { domestic miscellaneous water after secondary treatment and advanced treatment to } \\
\text { the total waste water. }\end{array}$ \\
\hline
\end{tabular}


Population Sub-System

The population sub-system studies the impact of population changes on water resources, the economy, and the environment. Demographic changes are reflected by factors such as total population and population growth rates. Population distribution and urban progress are reflected by factors such as urban population, rural population, and urbanization rate.

The total population was selected as the flow variable of the population sub-system, and its stock is mainly affected by the birth rate, mortality, and mechanical growth of the population. As the total population includes both urban and rural populations, there are differences in urban water demand and wastewater discharge in both urban and rural populations, and the demand for water resources will increase during the process of urbanization, the urbanization rate was introduced into the population sub-system to associate the population sub-system with several other sub-systems.

The state variable in the population sub-system is the total population, the rate variable is the population increase, and the remaining variables are auxiliary variables. The population sub-system variables are shown in Table 1. The structure of the population sub-system is shown in Figure 4.

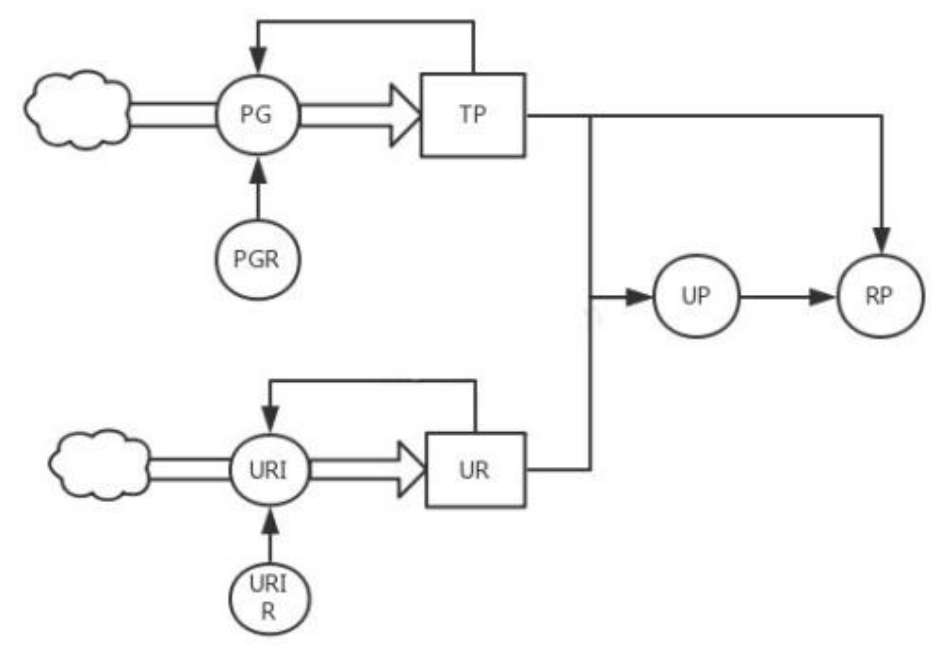

Figure 4. Population Subsystem of the Tianjin Water Resources Sustainable Utilization Model.

\section{Economic Sub-System}

The economic sub-system mainly studies the changes in economic growth and their impact on water resources, population, and the environment. Economic growth, taking the growth of the industrial economy as an example, will increase industrial water consumption, deepen the contradiction between the supply and demand of water resources, and further the irrational discharge of industrial "three wastes", causing the pollution of water resources [25]. However, economic growth will also improve production technology, increase the reuse rate of industrial water, and promote further industrial development.

The development of agricultural economy is similar to the development of industrial economy. On one hand, increases in the sown area of crops will cause changes in the area of arable land, the amount of water used for irrigation, and the amount of discharged wastewater will increase. On the other hand, in order to increase the output per unit area, the input of chemical fertilizers and pesticides will be increased, causing pollution to the land. However, economic growth will also bring about innovations in agricultural technology and promote further agricultural development.

Therefore, we must increase investment in environmental protection at the same time as economic development. Otherwise, focusing only on economic development and ignoring pollution caused by such development will inhibit sustainable economic development [26]. The state variables in the economic sub-system include GDP and total industrial water use, the rate variables include GDP increase and industrial water increase, and the remaining variables are auxiliary variables. The economic 
sub-system variables are shown in Table 1. The structure of the economic sub-system is shown in Figure 5.

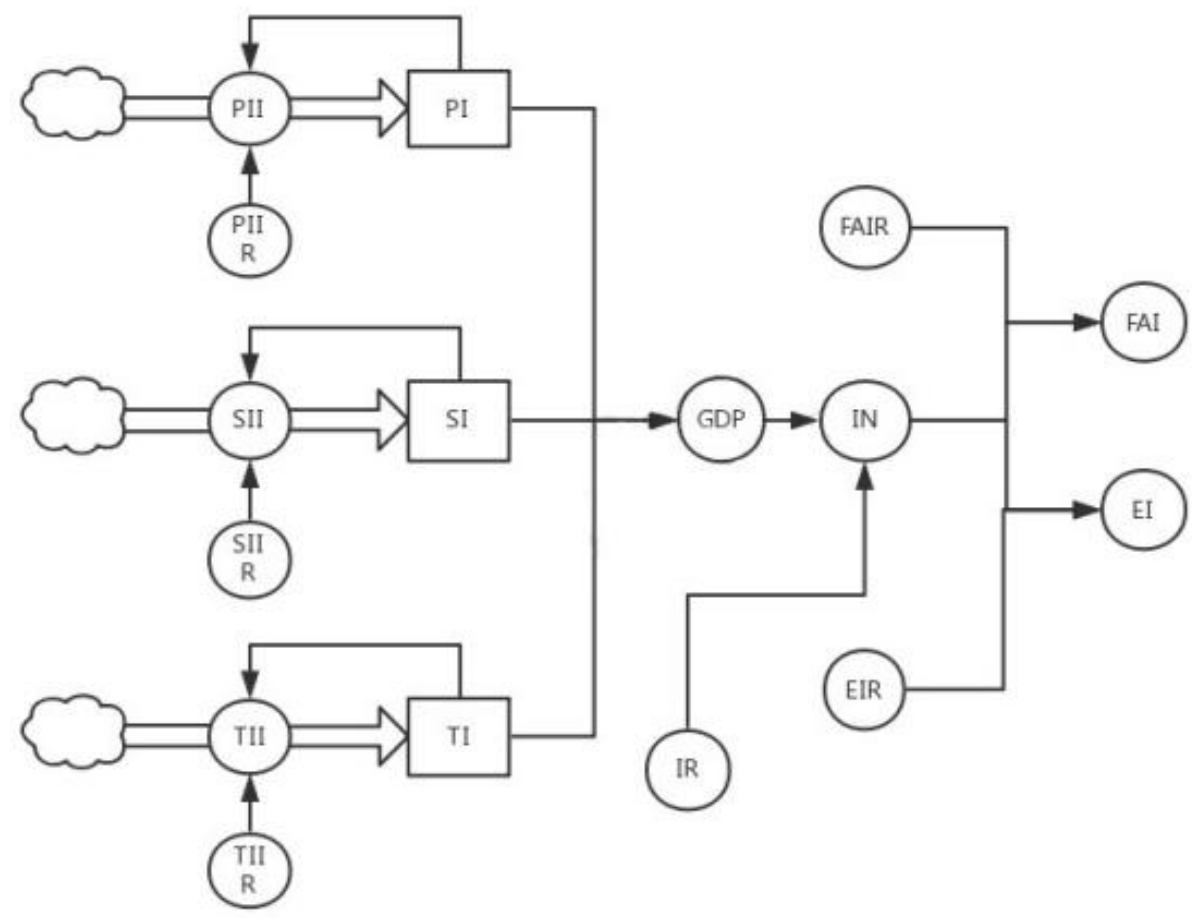

Figure 5. Economic Subsystem of the Tianjin Water Resources Sustainable Utilization Model.

Water Supply Sub-System

The water supply sub-system mainly studies the supply and demand trends of domestic water, industrial water, agricultural water, and ecological water under different population and economic development conditions, exploring the impact of water resources systems on population, economic, and environmental systems. The water supply sub-system consists of four parts: surface water, groundwater, desalination, and wastewater reuse. The direct utilization of seawater is considered separately and is not included in the total water supply.

The surface water source is mainly comprised of two types of water: one is the local surface water and the inbound water, the two kinds of water which are mainly used for agricultural irrigation and ecological water; the second is the water from the river and the groundwater, which are the main sources of water. The groundwater supply includes three parts: shallow water, deep water, and geothermal water.

The sewage treatment reuse amount refers to the reuse amount after centralized treatment by a sewage treatment plant, excluding the reuse amount of wastewater treatment within enterprises. The main areas of sewage treatment reuse are agricultural and ecological, from which sewage is treated in depth and mainly used for industrial production. Regression analyses of environmental protection investment rate and sewage reuse rate were carried out using mathematical software. The reuse rate of sewage can be calculated based on the investment rate of environmental protection in that year. The higher the rate of investment in environmental protection, the higher the reuse rate of sewage. Desalination water supply refers to the amount of water supplied by seawater processed by desalination facilities.

The water supply sub-system variables are shown in Table 1 . The structure of the water supply sub-system is shown in Figure 6. 


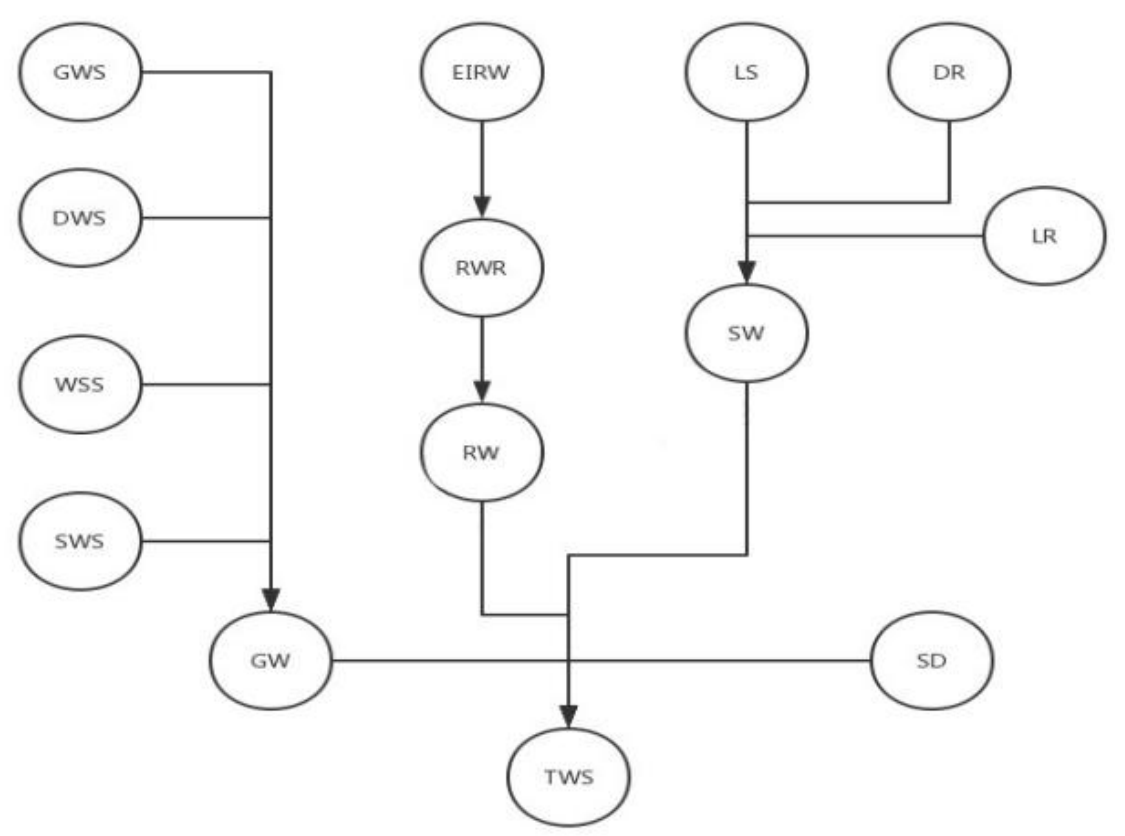

Figure 6. Tianjin Water Resources Sustainable Utilization Model.

Water Demand Sub-System

This sub-system uses water resources as an indicator. Water resources utilization refers to the total amount of gross water used by all types of water consumers, including water loss, according to four types of statistics: domestic, agricultural, industrial, and ecological (excluding direct seawater utilization). Agricultural water includes four types: irrigation, fishpond, livestock, and forest and fruit water. Industrial water consists of two parts: the tap water network and unconventional water sources. Among these, the tap water network includes groundwater captive wells and water diversion from rivers, and unconventional water sources include seawater desalination direct supply and deep treatment sewage reuse. Domestic water consists of two parts: domestic water and public water. The domestic water of residents is composed of the domestic water of urban residents and the domestic water of rural residents. The sum of the two is the amount of water used by residents:

Domestic water for residents $=$ domestic water for urban residents + domestic water for rural residents

Ecological water is mainly used to replenish the Yangtze River and other landscape rivers, and a small amount of groundwater for the urban environment. The water resources demand sub-system variables are shown in Table 1 . The structure of the water demand sub-system is shown in Figure 7.

\section{Water Environment Sub-System}

This sub-system includes the two major elements of chemical oxygen demand discharge and ammonia nitrogen discharge, which reflect the pollution degree of domestic sewage and industrial wastewater in environmental water. Both chemical oxygen demand and ammonia nitrogen emissions are generated from domestic water, agricultural water, industrial water, and ecological water; that is, from total water consumption. The environmental sub-system mainly considers quantifiable wastewater pollution in the "three wastes" pollution. Based on the current status of water pollution in Tianjin, the discharge of COD and ammonia nitrogen pollutants in wastewater were also considered when considering wastewater pollution. A large population will increase the discharge of domestic pollutants. Once the environment is seriously polluted, the mortality rate will increase, which will restrain population growth; the same is true for economic development. The excessively rapid development of the industrial economy will increase the pollution of industrial wastewater, waste 
gas, and solid waste, and the resultant severe pollution will inhibit the continued development of the economy. However, increasing the level of investment in environmental protection during economic development can reduce economic losses caused by environmental pollution.

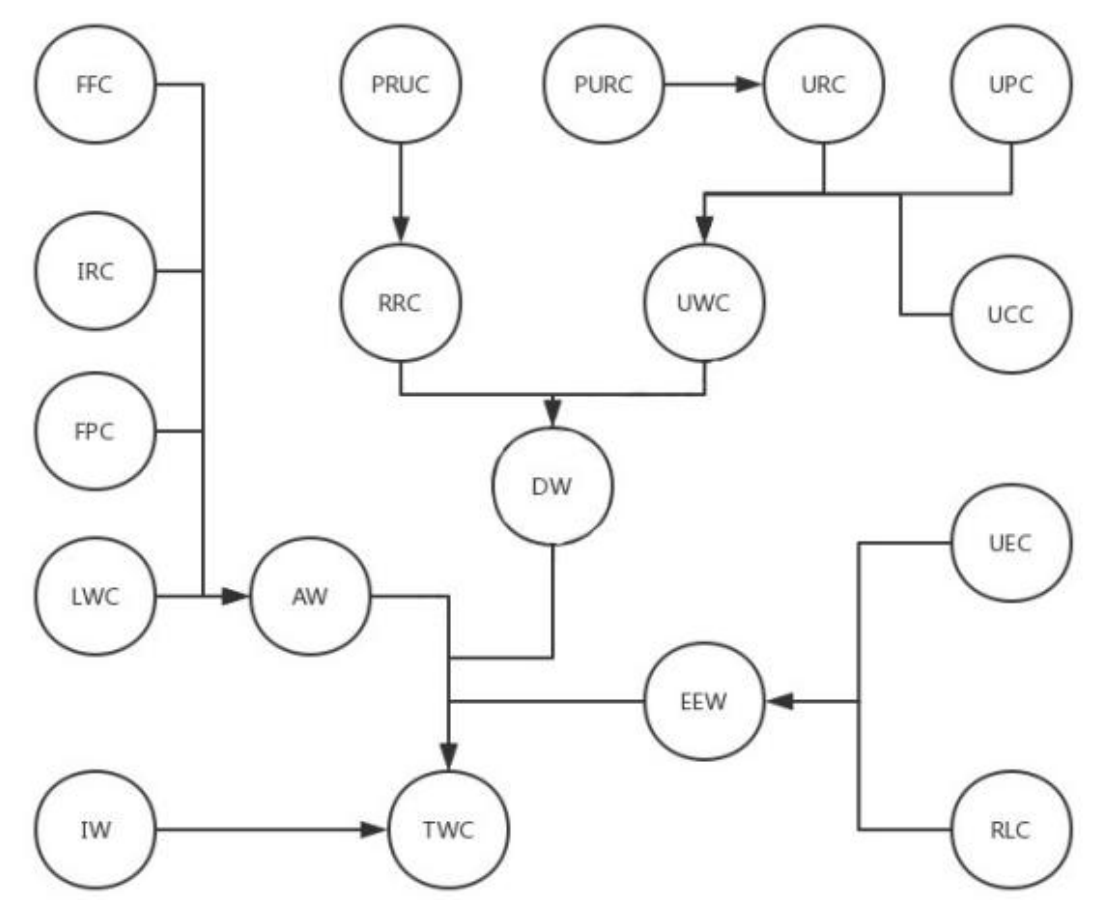

Figure 7. Tianjin Water Resources Sustainable Utilization Model.

The water environment sub-system variables are shown in Table 1. The structure of the water environment sub-system is shown in Figure 8.

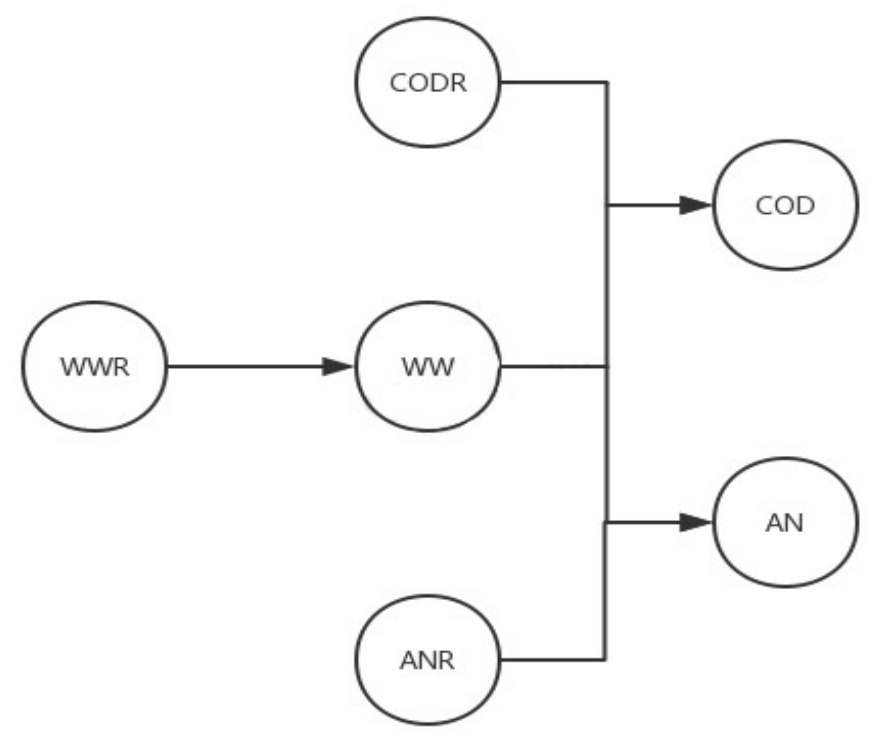

Figure 8. Water Environment Subsystem of Tianjin Water Resources Sustainable Utilization Model.

\subsubsection{Model Calibration and Verification}

System dynamics models are guided by qualitative analysis and supported by quantitative analysis. This requires that, in the modeling process, the model must be closely integrated with the actual situation; in-depth investigation and research must be conducted, and the collection and use of information and statistical data about the system and its problems must be maximized [27]. The validation test 
performed in the system dynamics modeling process is mainly a historical test; that is, the historical parameters are input to the model and the simulation results are obtained after running. The actual results are compared with the actual behavior data to verify the degree of agreement, and the reliability and accuracy of the model behavior can then be judged [28].

Our inspection items included the population, economic (industry, agriculture, and tertiary industries), water environment, and water resources sub-systems. The tested variables were SW, SD, RW, GW, TWS, AW, DW, EEW, IW, TWC, AN, COD, WW, TP, RP, UP, EI, FAI, and GDP.

\subsubsection{Sensitivity Analysis}

In order to determine the factors that had a greater impact on the sustainable use of water and water quality in Tianjin from 2018 to 2025, it was necessary to perform a model sensitivity analysis [29]. Ten state variables, such as effective farmland irrigation coefficient, domestic water quota growth rate, and sewage reuse rate, were selected as parameters for the sensitivity analysis, and the water resources shortage rate was used as the response target for sensitivity, using Equation (2) for analysis:

$$
S^{2}{ }_{\theta}=\left(\Delta x / x^{*}\right) /\left(\Delta \theta / \theta_{0}\right)
$$

where the sensitivity $S^{2}{ }_{\theta}$ represents the ratio of the change rate of the state variable $x$ relative to the original value $\mathrm{x}^{*}$ and the change rate of the parameter $\theta$ relative to $\theta_{0}$ around $\theta=\theta_{0}$. If the sensitivity of a parameter is greater than 1, the water supply and demand situation is more sensitive to the parameter. The larger the absolute value is, the more sensitive it is; otherwise, if the sensitivity is less than 1 , it is less sensitive to the parameter and, the smaller the absolute value, the less sensitive it is.

\subsubsection{Scenario Analysis}

In order to compare the sustainable use of water resources in Tianjin under different development scenarios, several variables with the highest sensitivities were selected as decision variables. Using different values for the decision variables, we designed four scenarios to analyze the sustainable development of water resources in Tianjin from 2019 to 2025. These four scenarios were status quo, water supply, economic development, and comprehensive.

Scenario 1 was the status quo, in which the current situation was unchanged and no measures were taken.

Scenario 2 was the water supply type: based on the status quo, the speed of economic development was reduced, the rate of environmental protection investment and urbanization was increased, the rate of wastewater generation was reduced, and the supply of water resources was increased.

Scenario 3 was the economic development type: with the development of the economy as the focus, related indicators (e.g., the GDP growth rate of the tertiary industries) were adjusted to be higher than their status quo levels.

Scenario 4 was comprehensive: factors such as population, economy, and technological development level were comprehensively considered, with a view towards long-term development. All indicators were centered and harmonized.

\section{Results Analysis}

\subsection{Model Calibration Results}

Based on the water supply data published in the Tianjin Water resources Bulletin 2013-2016, the model was calibrated, and the relative errors were calculated. The results are shown in Table 3. 
Table 3. 2013-2016 Tianjin Water Resources Supply, Demand, Water Environment, Population and Economic Rating Data Table.

\begin{tabular}{|c|c|c|c|c|c|c|c|c|c|c|c|}
\hline Years & Projects & SW & SD & RW & GW & TWS & AW & DW & EEW & IW & TWC \\
\hline \multirow{3}{*}{2013} & Actual value & 16.23 & 0.31 & 1.52 & 5.69 & 23.76 & 12.17 & 5.32 & 1.20 & 5.37 & 23.76 \\
\hline & Analog value & 16.15 & 0.33 & 1.45 & 5.78 & 23.72 & 12.25 & 5.03 & 1.20 & 5.33 & 23.81 \\
\hline & Relative error $/ \%$ & 0.47 & 6.46 & 4.66 & 1.61 & 0.15 & 0.66 & 5.49 & 0.10 & 0.69 & 0.23 \\
\hline \multirow{3}{*}{2014} & Actual value & 18.03 & 0.37 & 2.44 & 5.34 & 26.18 & 11.40 & 5.25 & 4.17 & 5.36 & 26.18 \\
\hline & Analog value & 17.63 & 0.35 & 2.23 & 5.53 & 25.73 & 12.13 & 5.26 & 4.02 & 5.38 & 25.99 \\
\hline & Relative error $/ \%$ & 2.24 & 3.84 & 8.74 & 3.50 & 1.73 & 6.40 & 0.16 & 3.51 & 0.28 & 0.73 \\
\hline \multirow{3}{*}{2015} & Actual value & 18.96 & 0.42 & 2.48 & 4.92 & 26.77 & 12.33 & 5.12 & 3.99 & 5.34 & 26.77 \\
\hline & Analog value & 18.75 & 0.36 & 2.68 & 5.32 & 27.11 & 11.89 & 5.48 & 4.30 & 5.42 & 27.19 \\
\hline & Relative error $/ \%$ & 1.08 & 13.48 & 7.95 & 7.96 & 1.26 & 3.61 & 6.94 & 7.86 & 1.53 & 1.56 \\
\hline \multirow{3}{*}{2016} & Actual value & 19.49 & 0.35 & 3.08 & 4.73 & 27.65 & 12.05 & 5.59 & 4.49 & 5.53 & 27.65 \\
\hline & Analog value & 19.71 & 0.37 & 3.24 & 5.12 & 28.43 & 11.59 & 5.71 & 4.54 & 5.47 & 28.00 \\
\hline & Relative error/\% & 1.09 & 4.06 & 5.35 & 8.32 & 2.81 & 3.82 & 2.24 & 1.03 & 1.06 & 1.26 \\
\hline Years & Projects & AN & COD & WW & TP & $\mathbf{R P}$ & UP & EI & FAI & GDP & \\
\hline \multirow{3}{*}{2013} & Actual value & 2.48 & 22.15 & 5.95 & 1472.21 & 264.85 & 1207.36 & 148.37 & $10,091.04$ & $14,689.94$ & \\
\hline & Analog value & 2.57 & 23.55 & 5.42 & 1472.21 & 264.85 & 1207.36 & 160.52 & $10,807.90$ & $14,659.90$ & \\
\hline & Relative error $/ \%$ & 3.66 & 6.31 & 8.93 & 0.00 & 0.00 & 0.00 & 8.19 & 7.10 & 0.20 & \\
\hline \multirow{3}{*}{2014} & Actual value & 2.45 & 21.43 & 5.92 & 1516.81 & 268.78 & 1248.03 & 220.92 & $11,626.27$ & $16,002.98$ & \\
\hline & Analog value & 2.39 & 21.62 & 5.84 & 1474.06 & 258.41 & 1215.64 & 239.90 & $11,454.90$ & $16,161.30$ & \\
\hline & Relative error $/ \%$ & 2.39 & 0.87 & 1.37 & 2.82 & 3.86 & 2.60 & 8.59 & 1.47 & 0.99 & \\
\hline \multirow{3}{*}{2015} & Actual value & 2.38 & 20.91 & 5.99 & 1546.95 & 268.55 & 1278.40 & 240.56 & $13,047.76$ & $16,837.86$ & \\
\hline & Analog value & 2.15 & 19.64 & 6.35 & 1476.05 & 253.63 & 1222.42 & 217.91 & $11,840.40$ & $17,229.40$ & \\
\hline & Relative error $/ \%$ & 9.83 & 6.07 & 6.07 & 4.58 & 5.56 & 4.38 & 9.41 & 9.25 & 2.33 & \\
\hline \multirow{3}{*}{2016} & Actual value & 1.57 & 10.33 & 6.77 & 1562.12 & 266.65 & 1295.47 & 201.98 & $11,223.52$ & $17,885.39$ & \\
\hline & Analog value & 1.64 & 10.27 & 6.79 & 1478.21 & 249.84 & 1228.37 & 197.14 & $11,762.40$ & $17,955.00$ & \\
\hline & Relative error/\% & 4.69 & 0.61 & 0.35 & 5.37 & 6.31 & 5.18 & 2.39 & 4.80 & 0.39 & \\
\hline
\end{tabular}

Explanation: The unit of actual and simulated values in the table is 100 million cubic meters.

\subsection{Model Verification Results}

The model was verified with the water supply data published in the 2017 Tianjin Water Resources Bulletin, and the relative errors were calculated. The results are shown in Table 4.

Table 4. Verification data table of Tianjin's water supply, demand, water environment, population and economy in 2017.

\begin{tabular}{|c|c|c|c|c|c|c|c|c|c|c|c|}
\hline & Projects & SW & SD & RW & GW & TWS & AW & DW & EEW & IW & TWC \\
\hline \multirow[t]{2}{*}{2017} & Analog value & 20.57 & 0.37 & 3.64 & 4.93 & 29.52 & 11.26 & 5.96 & 5.89 & 5.51 & 28.62 \\
\hline & Projects & AN & COD & WW & TP & $\mathbf{R P}$ & UP & EI & FAI & GDP & \\
\hline \multirow{2}{*}{2017} & Actual value & 1.42 & 9.26 & 7.05 & 1556.87 & 265.76 & 1291.11 & 78.51 & $11,274.69$ & $18,549.19$ & \\
\hline & Relative error $/ \%$ & 2.95 & 3.03 & 1.81 & 4.90 & 7.15 & 4.44 & 0.75 & 3.30 & 0.31 & \\
\hline
\end{tabular}

Explanation: The unit of actual and simulated values in the table is 100 million cubic meters.

After testing, the simulation results of the model were basically consistent with the historical development results, and the errors did not exceed 10\%. Therefore, it can be considered that the simulation results were in line with historical development [30] The model basically conformed to the research system, and the parameters of the model could confidently be used in the prediction stage of the model.

\subsection{Sensitivity Analysis Results}

As can be seen from Table 5, the results of the sensitivity analysis show that the urbanization rate, environmental protection investment rate, tertiary industry GDP growth rate, and wastewater generation rate were the four most sensitive variables. 
Table 5. Model parameters sensitivity.

\begin{tabular}{cc}
\hline Parameter & Sensitivity \\
\hline Natural growth rate & -0.08 \\
Urbanization rate growth rate & 5.69 \\
Investment rate & -1.31 \\
Environmental Investment Rate & 3.78 \\
Fixed Asset Investment Rate & -0.03 \\
Wastewater generation rate & 4.52 \\
Wastewater reuse rate & 0.06 \\
Growth rate of primary industry GDP & -0.02 \\
GDP growth rate of the secondary industry & 0.01 \\
Growth rate of tertiary industry GDP & 1.34 \\
\hline
\end{tabular}

\subsection{Scenario Simulation Results}

We selected the four most sensitive variables as decision variables. These four variables were urbanization rate, environmental protection investment rate, tertiary industry GDP growth rate, and wastewater generation rate. The specific sensitivity parameters are shown in Table 6.

Table 6. Sensitivity parameters in different scenarios.

\begin{tabular}{lcccc}
\hline & UR/\% & EIR/\% & TIIR/\% & WWR/\% \\
\hline Scenario 1 & 84.01 & 1.17 & 10.6 & 3.48 \\
Scenario 2 & 86.01 & 1.57 & 5.6 & 2.78 \\
Scenario 3 & 86.01 & 1.57 & 13.6 & 3.38 \\
Scenario 4 & 82.01 & 1.07 & 9.6 & 3.38 \\
\hline
\end{tabular}

\subsubsection{Water Supply and Demand Analysis}

As shown in Figure 9, in the four scenarios, the total water consumption under maintenance of the status quo increased slowly, with a relatively stable growth rate. The water supply scenario also maintained an increasing trend, but the growth rate changed from low to high and then stabilized. This may be due to the impact of the increase in water supply capacity on resident's water habits, resulting in increased water consumption. The difference between the total water consumption in the economic development scenario in the first three years, as compared to the status quo scenario, was small; however, the gap gradually widened, and the trend declined after reaching a peak in 2021, which may be due to further development of the economy, promoting the improvement of industrial technology and further saving part of the water resources as an ideal solution. The total water consumption in the comprehensive scenario slowly increased, and was 114 million cubic meters lower than that in the status quo scenario in 2025. Among the four scenarios, the growth rate of the water consumption was slowest in the last scenario, and it presents a great advantage in addressing long-term water shortage problems.

As shown in Figure 10, in the four scenarios, the total water supply when maintaining the status quo has a slowly increasing trend, and the total water supply in 2025 will be 3.066 billion. The total water supply under the water supply scenario in 2025 is 3.637 billion, which is the largest of the four scenarios. The reason for this is that the amount of sewage is small, and the reuse rate of sewage is the same as that of the status quo. As a result, the amount of reused sewage is correspondingly reduced, and the amount of water supply is increased. The total water supply under the economic development scenario is 3.278 billion in 2025. The impact of water use was slower than when maintaining the status quo, and most wastewater produced was industrial. The total water supply under the comprehensive scenario is second only to the water supply scenario and it is 368 million more than the status quo scenario by 2025 . 


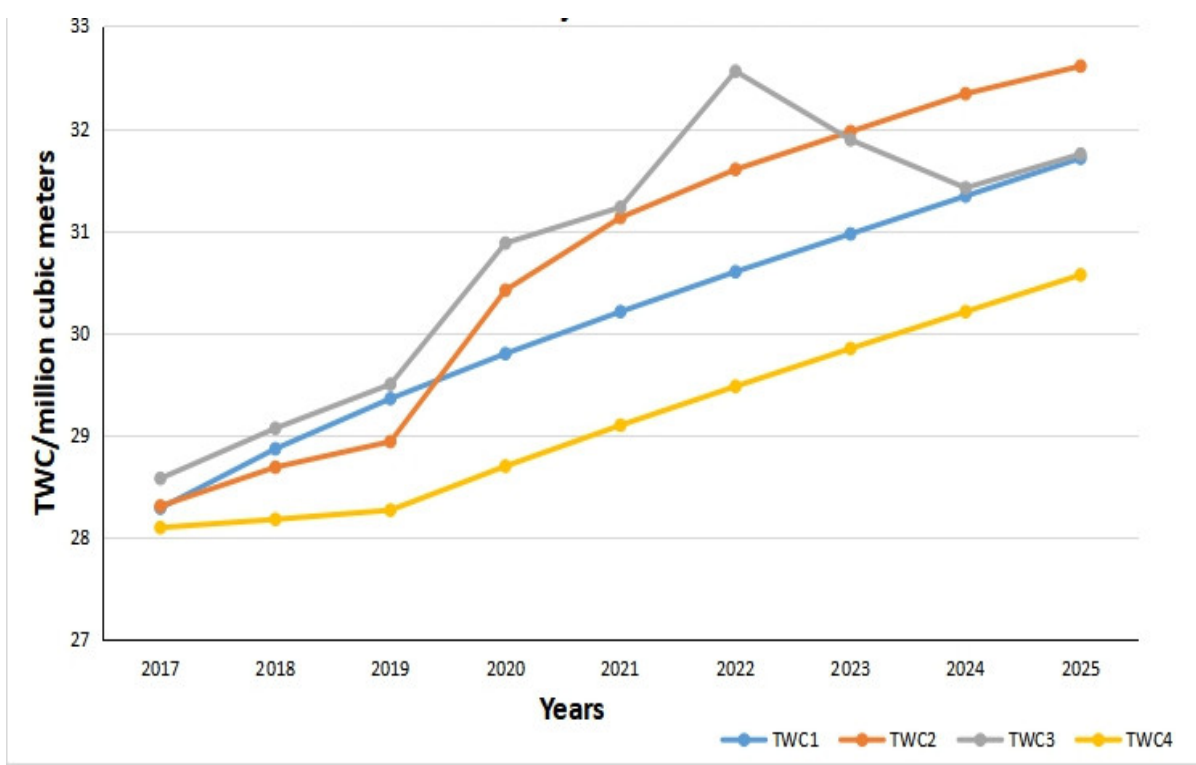

Figure 9. Trends of total water consumption over time under four simulated scenarios in Tianjin from 2017 to 2025.

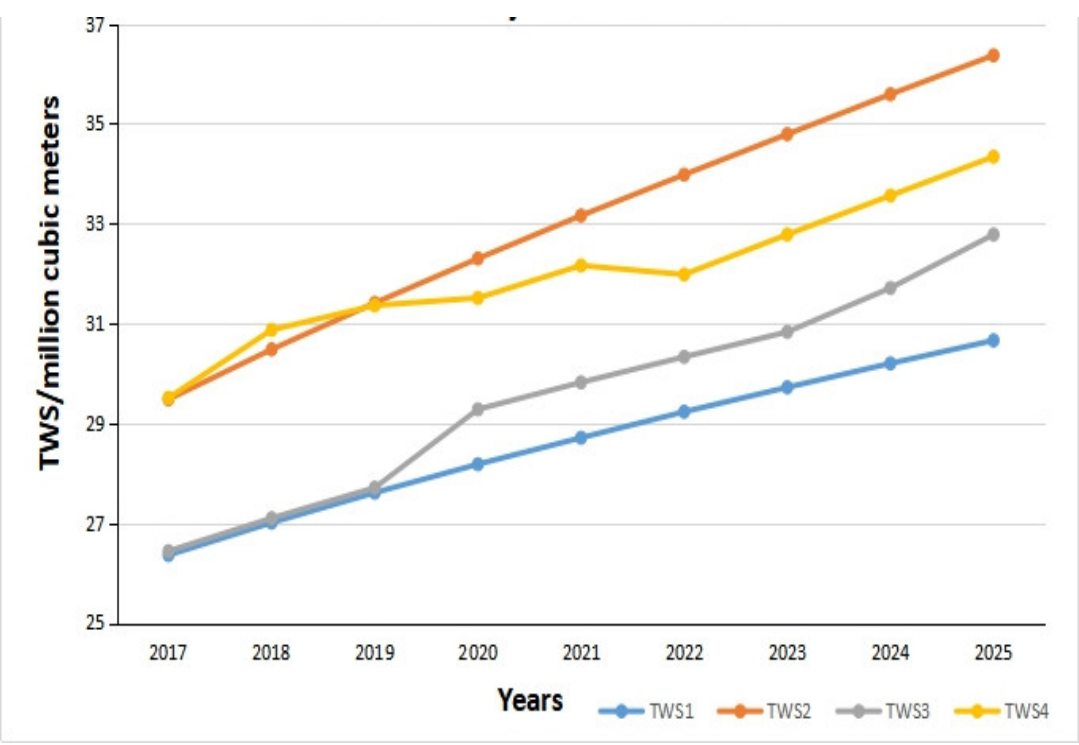

Figure 10. Trends of total water supply over time under four simulated scenarios in Tianjin from 2017 to 2025 .

The difference between water supply and demand is the most important parameter to measure water supply pressure [31]. As shown in Figure 11, in the four scenarios, the current supply balance in 2017 maintained a negative value of 193 million cubic meters, from which the problem of insufficient supply of water resources became apparent. The shortage of water resources gradually decreases to a minimum of 20 million cubic meters in 2025, putting great pressure on the water supply system. 


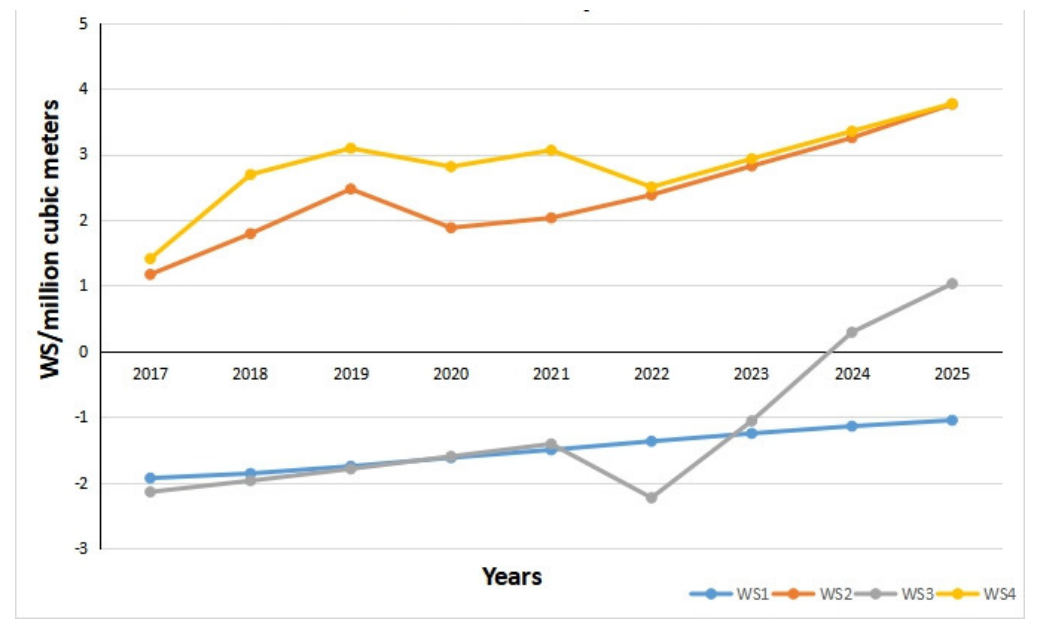

Figure 11. Trends of water supply and demand gaps over time under four simulated scenarios in Tianjin from 2017 to 2025.

The water supply scenario was very effective in solving the problem of water shortage. The supply and demand difference was positive, and the fastest effect was achieved. The water supply scenario's supply and demand difference increased over time. However, this was achieved only by increasing the external water replenishment; after the water replenishment has risen to a certain level, there is little room for improvement, such that the increase in water supply pressure in the later period is the second largest, behind maintaining the status quo. The supply and demand surplus in 2025 will be 376 million cubic meters. In the four schemes, the water supply pressure in this scenario was only smaller than that of the comprehensive scenario.

The economic development scenario was slow to take effect. At the beginning, the gap between it and the status quo scenario was small, and the gap between them only gradually widened. In 2017, the supply-demand balance showed a negative value of 214 million cubic meters, followed by decreasing, then increasing, and then decreasing again. By 2025, the supply exceeded the demand, and the supply-demand surplus was 103 million cubic meters. Putting pressure on the water supply system also increases competition for water resources among the various water sub-systems.

In the comprehensive scenario, the supply-demand balance improved significantly in the first year, and both were positive. The growth rate was also higher than the water supply type, which can basically solve the water shortage problem. The supply-demand surplus in 2025 was 377 million, which was the largest of the four scenarios.

\subsubsection{Water Quality Changes}

If the status quo development is maintained, in accordance with Scenario 1, the total sewage discharge and COD and ammonia nitrogen emissions in Tianjin slowly decrease, and the level of water pollution in Tianjin improves. Under Scenario 2, the total amount of COD and ammonia nitrogen emissions in Tianjin continuously reduce, but the increase rate of wastewater discharge is high, indicating that economic development constrains COD and ammonia nitrogen emissions. Under Scenario 3, the increase rate of sewage discharge is the lowest of the four scenarios; however, the COD and ammonia nitrogen emissions increase, indicating that industrial sources have a greater constraint on sewage discharge. Under Scenario 4, the total amount of COD emissions continuously reduce, sewage discharge increases by $9.5 \%$, COD emissions decrease by $5.1 \%$, and ammonia nitrogen emissions decrease by $12.6 \%$. It can be seen that, in order to improve the water pollution situation in Tianjin, it is not enough to rely on a single method to regulate and control. Instead, multiple aspects must be considered.

Therefore, Scenario 4 can be considered the optimal solution for the sustainable development of Tianjin's water environment. 


\subsubsection{Comprehensive Analysis}

Keeping all parameters of the status quo unchanged, Scenario 1 was used for comparison with the simulation results of the other scenarios. According to the current development trend, the water demand increases year by year. The total water consumption in 2025 will reach 3.171 billion cubic meters, an increase of 342 million cubic meters compared with 2017. The total water supply is only 3.066 billion cubic meters, an increase of 430 million cubic meters over 2017, and the shortage of water supply and demand in 2025 will reach 105 million cubic meters. If the current situation continues to develop, the shortage of water resources in Tianjin can only be alleviated by continuously increasing externally diverted water, which makes it the most detrimental scenario, in terms of the sustainable use of water resources.

Scenario 2 was a water supply model, with a total water consumption of 3.261 billion cubic meters in 2025 and a surplus of 376 million cubic meters in supply and demand. Compared with the status quo, under the same water consumption, the water supply increased significantly, and the shortage of water improved. The water-supply scenario had a good effect, which was the fastest and had the least cost of adjustment. The disadvantage is that, at the beginning, its improvement is large, but its staying power is insufficient, as the water supply capacity is limited. In order to increase the water supply to a certain extent, the economic input cost must also be increased.

Scenario 3 was focused on economic development, with a total water supply of 3.278 billion cubic meters in 2025. The economic development approach is to appropriately slow down the development of industries and to vigorously develop tertiary industries. The total water demand is 3.175 billion cubic meters, which is 86 million cubic meters less than the status quo model. The supply and demand surplus is 103 million cubic meters. The shortage of water resources is slightly improved, compared to the status quo model. The economic development type is conducive to reducing water consumption and is in line with the direction of Tianjin's economic development. The disadvantage is that it can only reduce industrial water use; it has no effect on other water consumption behaviors, such as domestic and agriculture.

Scenario 4 was a comprehensive scenario, formed on the basis of water saving, industrial structure adjustment, and non-traditional water sources. In 2025, the total water consumption will be 3.057 billion cubic meters, and the total water supply will be 3.434 billion cubic meters, which can better meet the water demand.

The comprehensive approach takes into account measures such as water conservation, industrial restructuring, and water recycling, which can effectively reduce water consumption and increase water supply, basically addressing the water shortage problem in Tianjin. It has a quick effect and long-term effectiveness, which is conducive to the coordinated development of society, economy, and water resources, and meets the requirements of sustainable development. Its disadvantage is that it needs to take measures in various aspects; unlike the other three programs, which can focus on human, material, or financial resources to focus on improving just one aspect.

In general, the comprehensive type is the most reasonable and effective solution.

\subsection{Discussions}

Research into the sustainable use of water resources involves many factors, including economic, social, and environmental aspects. Due to the limited level, time, and insufficient data, the model in this article only selected a few of the many possible influencing factors, and there are still many factors which have not been taken into account. Some variables failed to find planned values and relied solely on existing trends for prediction. At the same time, due to the limitations of the data sources, the data series in this paper had a short time step, which had an impact on the accuracy of the prediction results of the model.

The complex, systematic, and particular characteristics of the sustainable use of water resources present difficulties in allowing the theoretical and applied study of sustainable use of water resources to meet actual needs. There are many issues that need to be further studied in depth, in order to conduct 
a more comprehensive analysis of water resources-related factors and to improve the accuracy of prediction. In the future, when studying the sustainable use of water resources, various mathematical models may be combined with system dynamics models, in order to benefit from their individual strengths. Ultimately, the trend prediction of water resources utilization must be made more accurate and reasonable.

\section{Conclusions and Suggestions}

\subsection{Conclusions}

In this paper, we considered the situation of water resources in Tianjin's five major sectors, built a system dynamics model, and simulated water resources utilization in Tianjin with good results. The results show that the contradiction between supply and demand of water resources in Tianjin becomes more prominent. In 2025, the demand for water resources in Tianjin will reach 3.174 billion cubic meters. Four parameters were selected, in order to form four different scenarios in simulating the development of water resources in Tianjin from 2017 to 2025. The results show that the comprehensive scenario had the optimal allocation; that is, it was the most beneficial for the sustainable development of water resources.

In short, comprehensive allocation provides a means to address the problem of water resource shortages. Relying on increasing water supply has certain limitations; it cannot completely solve the problem of water shortage and is not conducive to the sustainable use of water resources. It is necessary to increase water consumption while increasing water supply. The traditional method of increasing water supply in Tianjin is the water transfer project, but its cost is higher and dependence on it is stronger. According to the actual situation in Tianjin, open-source methods which can be further adopted are rainwater collection and sewage reuse. To achieve the sustainable development of water resources, we should start from these two aspects, learn advanced technologies, increase investment, and reduce the burden on water supply systems.

\subsection{Strategy Recommendations}

Based on the design, comparison, and analysis of the above four scenarios, the following suggestions are made for the use of water resources in Tianjin.

(1) Save water: Water-saving measures have lower cost and quick effect, which can effectively alleviate the pressure of water supply and, at the same time, reduce the discharge of sewage, which is conducive to the improvement of the water environment. It is the only way for sustainable use of water resources;

(2) Industrial structure adjustment: The development of tertiary industries is an important sign of economic modernization and industrial structure optimization. Increasing the proportion of the tertiary industry can significantly reduce the total water consumption. Therefore, for industries with large water consumption, such as textiles, petrochemicals, steel machinery, and other industries, water consumption quotas must be strictly controlled. For projects with high water consumption and low benefits, consideration should be given to eliminating or forcibly reducing water consumption. The development of industries with low water consumption and the construction of ecological industrial parks should be encouraged, and priority should be given to the development of high-tech industries, industries with low water consumption, and high-efficiency industries;

(3) Open-source: The traditional method for increasing the water supply in Tianjin is the water transfer project, but its cost is high and dependence on it is strong. The problem of insufficient water supply can only be fundamentally solved by improving the city's own water supply capacity. The potential for surface water and groundwater exploitation in Tianjin is limited, especially as deep groundwater is difficult to recover in the short term; however, the utilization rate of non-traditional water sources is very low, and there is still a lot of room for such expansion. 
According to Tianjin's situation, the available non-traditional water sources are treated sewage, seawater, and rainwater;

(4) Strengthen the management plan for water resources: Water affairs departments should constantly improve the relevant laws and regulations and management systems for water resources management, in accordance with changes in actual conditions, increase the supervision of government departments at all levels, and scientifically manage water resources. External interference should be avoided as much as possible. It is necessary to continuously learn advanced foreign technologies and experiences, and to explore the sustainable use of water resources in accordance with the actual situation of local conditions;

(5) For supply and demand: In resource-constrained cities such as Tianjin, water resources planning can be considered in the form of supply and demand. According to the total amount of available water resources and the actual situation of water use, the relationship between the economy, environment, and water resources should be coordinated; water resources should be scientifically allocated; and a reasonable water consumption quota should be determined. A water consumption unit should allocate water according to the quota, which can ensure the balance between supply and demand and avoid unnecessary waste.

Author Contributions: C.L. conceived and designed the research; Y.T. wrote the paper; Y.Y. performed the research; X.W. analyzed the data; A.S. contributed reagents/materials/analysis tools. All authors have read and agreed to the published version of the manuscript.

Funding: This study is supported by the National Key Research and Development Program (2017YFC0404401 and 2018YFC0407403).

Acknowledgments: We would like to extend special thanks to the editor and reviewers for insightful advice and comments on the manuscript.

Conflicts of Interest: The authors declare no conflict of interest.

\section{References}

1. Shi, C.; Wang, L. Sustainable utilization study and assessment of water resources in Chaohe river basin based on system dynamics. In Proceedings of the 2011 International Conference on Multimedia Technology, Hangzhou, China, 26-28 July 2011; pp. 3692-3695.

2. Erfani, T.; Huskova, I.; Harou, J.J. Tracking trade transactions in water resource systems: A node-arc optimization formulation. Water Resour. Res. 2013, 49, 3038-3043. [CrossRef]

3. Jin, L.; Chang, Y.; Ju, X.; Xu, F. A Study on the Sustainable Development of Water, Energy, and Food in China. Int. J. Environ. Res. Public Health 2019, 16, 3688. [CrossRef] [PubMed]

4. Yang, J.; Lei, K.; Khu, S.; Meng, W. Assessment of Water Resources Carrying Capacity for Sustainable Development Based on a System Dynamics Model: A Case Study of Tieling City, China. Water Resour. Manag. 2015, 29, 885-899. [CrossRef]

5. Ahmad, S.; Simonovic, S.P. Spatial system dynamics: New approach for simulation of water resources systems. J. Comput. Civ. Eng. 2004, 18, 331-340. [CrossRef]

6. Chen, C.; Ahmad, S.; Kalra, A.; Xu, Z.X. A dynamic model for exploring water-resource management scenarios in an inland arid area: Shanshan County, Northwestern China. J. Mt. Sci. 2017, 14, 1039-1057. [CrossRef]

7. Cheng, W.C.; Hsu, N.S.; Cheng, W.M.; Yeh, W.W.G. A flow path model for regional water distribution optimization. Water Resour. Res. 2009, 45, W09411. [CrossRef]

8. Xu, Z.X.; Takeuchi, K.; Ishidaira, H.; Zhang, X.W. Sustainability Analysis for Yellow River Water Resources Using the System Dynamics Approach. Water Resour. Manag. 2002, 16, 239-261. [CrossRef]

9. Zarghami, M.; Akbariyeh, S. System dynamics modeling for complex urban water systems: Application to the city of Tabriz, Iran. Resour. Conserv. Recycl. 2012, 60, 99-106. [CrossRef]

10. Xu, Z.; Yao, L.; Chen, X. Urban water supply system optimization and planning: Bi-objective optimization and system dynamics methods. Comput. Ind. Eng. 2020, 142, 106373. [CrossRef]

11. Kim, T.J.; Wurbs, R.A. Development of monthly naturalized flow using Water Rights Analysis Package (WRAP)-based methods. KSCE J. Civ. Eng. 2011, 15, 1299. [CrossRef] 
12. Dawadi, S.; Ahmad, S. Evaluating the impact of demand-side management on water resources under changing climatic conditions and increasing population. J. Environ. Manag. 2013, 114, 261-275. [CrossRef] [PubMed]

13. Sušnik, J.; Vamvakeridou-Lyroudia, L.S.; Savić, D.A.; Kapelan, Z. Integrated System Dynamics Modelling for water scarcity assessment: Case study of the Kairouan region. Sci. Total Environ. 2012, 440, 290-306.

14. Dai, S.; Li, L.; Xu, H.; Pan, X.; Li, X. A system dynamics approach for water resources policy analysis in arid land: A model for Manas River Basin. J. Arid Land 2013, 5, 118-131. [CrossRef]

15. Yang, J.; Lei, K.; Khu, S.; Meng, W.; Qiao, F. Assessment of water environmental carrying capacity for sustainable development using a coupled system dynamics approach applied to the Tieling of the Liao River Basin, China. Environ. Earth Sci. 2015, 73, 5173-5183. [CrossRef]

16. Li, Z.; Li, C.; Wang, X.; Peng, C.; Cai, Y.; Huang, W. A hybrid system dynamics and optimization approach for supporting sustainable water resources planningin Zhengzhou City, China. J. Hydrol. 2018, 556, 50-60. [CrossRef]

17. Sun, L.; Li, C.H.; Jia, X.L.; Wang, Y.; Cai, Y.P. Study on Forecast of Water Supply and Demand in Anhui Province Based on STELLA. J. Water Resour. Water Eng. 2015, 26, 51-57. (In Chinese)

18. Wang, B.; Cai, Y.; Tan, Q.; Hao, Y. An Integrated Approach of System Dynamics, Orthogonal Experimental Design and Inexact Optimization for Supporting Water Resources Management under Uncertainty. Water Resour. Manag. 2017, 31, 1665-1694. [CrossRef]

19. Tianjin Water Affairs Bureau. Tianjin Water Resources Bulletin; Tianjin Water Affairs Bureau: Tianjin, China, 2015. (In Chinese)

20. Wang, L.; Fang, L.; Hipel, K.W. Mathematical programming approaches for modeling water rights allocation. J. Water Resour. Plan. Manag. 2007, 133, 50-59. [CrossRef]

21. Kotir, J.H.; Smith, C.; Brown, G.; Marshall, N.; Johnstone, R. Johnstone. A system dynamics simulation model for sustainable water resources management and agricultural development in the Volta River Basin, Ghana. Sci. Total Environ. 2016, 573, 444-457. [CrossRef]

22. Li, Y.H.; Chen, P.Y.; Lo, W.H.; Tung, C.P. Integrated water resources system dynamics modeling and indicators for sustainable rural community. Paddy Water Environ. 2015, 13, 29-41. [CrossRef]

23. Sun, Y.; Liu, N.; Shang, J.; Zhang, J. Sustainable utilization of water resources in China: A system dynamics model. J. Clean. Prod. 2016, 142, 613-625. [CrossRef]

24. Xi, X.; Poh, K.L. A Novel Integrated Decision Support Tool for Sustainable Water Resources Management in Singapore: Synergies between System Dynamics and Analytic Hierarchy Process. Water Resour. Manag. 2015, 29, 1329-1350. [CrossRef]

25. Liang, Y.; He, W.J.; Degefu, D.M.; Liao, Z.Y.; Wu, X.; An, M.; Zhang, Z.F.; Ramsey, T.S. Transboundary Water Sharing Problem: A Theoretical Analysis Using Evolutionary Game and System Dynamic. J. Hydrol. 2020, $582,124521$.

26. Rixon, S.; Levison, J.; Binns, A.; Persaud, E. Spatiotemporal variations of nitrogen and phosphorus in a clay plain hydrological system in the Great Lakes Basin. Sci. Total Environ. 2020, 714, 136328. [CrossRef]

27. Ravar, Z.; Zahraie, B.; Sharifinejad, A.; Gozini, H.; Jafari, S. System dynamics modeling for assessment of water-food-energy resources security and nexus in Gavkhuni basin in Iran. Ecol. Indic. 2020, 108, 105682. [CrossRef]

28. Song, M.; Cui, X.; Wang, S. Simulation of land green supply chain based on system dynamics and policy optimization. Int. J. Prod. Econ. 2019, 217, 317-327. [CrossRef]

29. Qin, H.; Zheng, C.; He, X.; Refsgaard, J.C. Analysis of Water Management Scenarios Using Coupled Hydrological and System Dynamics Modeling. Water Resour. Manag. 2019, 33, 4849-4863. [CrossRef]

30. Bao, C.; He, D. Scenario Modeling of Urbanization Development and Water Scarcity Based on System Dynamics: A Case Study of Beijing-Tianjin-Hebei Urban Agglomeration, China. Int. J. Environ. Res. Public Health 2019, 16, 3834. [CrossRef]

31. Takeda, N.; López-Galvis, L.; Pineda, D.; Castilla, A.; Takahashi, T.; Fukuda, S.; Okada, K. Evaluation of water dynamics of contour-levee irrigation system in sloped rice fields in Colombia. Agric. Water Manag. 2019, 217, 107-118. [CrossRef]

(C) 2020 by the authors. Licensee MDPI, Basel, Switzerland. This article is an open access article distributed under the terms and conditions of the Creative Commons Attribution (CC BY) license (http://creativecommons.org/licenses/by/4.0/). 